\title{
La responsabilidad extracontractual del Estado por ejercicio del poder legislativo.
}

\author{
Non-contractual state liability \\ due exercise of legislative power
}

\author{
Pablo Andrés Proaño* \\ Investigador Jurídico independiente \\ Juan Antonio Benalcázar** \\ Investigador Jurídico independiente \\ Carlos José Rivadeneira*** \\ Investigador Jurídico independiente
}

Infomación del Artículo

Original - Ruptura, 2020

Artículo recibido / Received: 5 de octubre, 2020

Artículo aceptado / Accepted: 1 de diciembre, 2020

\section{Citación}

Proaño, P., Benalcázar, J. y Rivadeneira, C. (2020). La responsabilidad extracontractual del Estado por ejercicio del poder legislativo. Revista Ruptura de la Asociación Escuela de Derecho de la PUCE. Edición 2020, p. (347-376).

DOI: $10.26807 /$ rr.vi02.31

* $\quad$ Estudiante de noveno semestre de la Facultad de Jurisprudencia de la Universidad San Francisco de Quito.

** Estudiante de noveno semestre de la Facultad de Jurisprudencia de la Universidad San Francisco de Quito.

*** Estudiante de noveno semestre de la Facultad de Jurisprudencia de la Universidad San Francisco de Quito, Asistente de Cátedra de las materias: Derecho Penal II, Derecho Procesal Penal y Delitos de Peligro y Omisión en la Universidad San Francisco de Quito. Correo electrónico: crivadeneira1998@gmail.com. 
Resumen: "No es la validez, legalidad o inconstitucional de una norma, es el daño que provoca, el daño que genera un fuerte dolor a sus administrados" (Valdivia, 2019, p.113). Es necesario comprender la responsabilidad jurídica que debe tener un Estado de Derecho, quien a su vez es garante de que el sistema jurídico brinde la facultad de resarcir y hacer exigibles cada uno de los daños generados, sin importar su naturaleza, más aún aquellos que deriven de una irresponsabilidad legislativa, abordando figuras que conlleven a analizar el abuso del poder estatal, por tal motivo dentro del presente trabajo se expondrá cada uno de los supuestos de hecho mediante los cuales puede ser entendida esta institución denominada responsabilidad extracontractual producto de un hecho legislativo, mediante un proceso argumentativo conjunto que permita desarrollar aquellos requisitos fácticos y elementales para considerar la existencia de un daño que violente derechos entre el particular y el ente público que tengan como fundamento la inconstitucionalidad de una norma, su ilegalidad o en cierto caso violente una legítima expectativa de confianza legislativa con sus habitantes de quien podría ser imputado el presunto hecho antijurídico.

Palabras clave: Responsabilidad del Estado, responsabilidad extracontractual, derecho de daños, responsabilidad extracontractual del Estado legislador.

Abstract: "It is not the validity, legality or unconstitutionality of a norm, it is the damage it causes, the damage generated by strong pain to its administrators." (Valdivia, 2019, p.113). Starting from the same, it is necessary to understand the legal conscience that a rule of law must have, where they contemplate real ideals of freedom, security, and a number of positive laws that depend on each of the citizens, even the least prolific, of the same access to mechanisms of limitation, state control, so that in turn the Ecuadorian legal system provides the powers of investigation and make each of the damages caused by legislative irresponsibility enforceable, where the figures that involve an analysis of the prevailing abuse of state power, for this reason within this work arguing each of the assumptions of facts by which it can if this institution is liable for foreign contractual liability as a result of damage or legislative change, through a joint argumentative process that allows the development of the factual 
and elementary requirements to consider the existence of damage that violates rights between the individual and the public of whom it could be alleged illegal act.

Keywords: Responsibility of the State, extra-contractual responsibility, exemptions from extra-contractual responsibility, unlawful act, damage, extra-contractual responsibility of the legislating State.

\section{Introducción}

Para varios sistemas jurídicos modernos, la responsabilidad extracontractual del Estado es un tema reconocido por la doctrina, jurisprudencia y la normativa vigente. En la mayoría de los casos se habla con mucha claridad sobre la responsabilidad estatal respecto de actos administrativos; sin embargo, hay algunos sistemas jurídicos que amplían el rango de responsabilidad a otros actos estatales, como es el ejemplo de la responsabilidad del Estado legislador.

El presente trabajo académico pretende presentar la posibilidad de incorporar al ordenamiento ecuatoriano la responsabilidad extracontractual del Estado producto de un daño legislativo. Y en virtud de esto, permitir a los ciudadanos solicitar un resarcimiento, sustentándose en la errónea aplicación de la potestad legislativa del Estado que derive en daños.

Históricamente la posibilidad de reclamar frente al Estado era muy limitada, tanto que se otorgaba un "poder supremo" del Estado que no podían ser cuestionadas sus decisiones, argumentando que "la ley es un acto de soberanía, en tal virtud nadie puede ir contra de la voluntad del legislador y peor aún reclamar algún tipo compensación si sufriese algún daño directo de dicha voluntad" (Alonso, Leiva, 2011, p.80).

Básicamente se eximia de cualquier responsabilidad a los legisladores quienes en ejercicio de su función producían un cambio de ley sin contemplar los alcances de la norma promulgada, alcances que, en ciertos casos, podría causar daños a los particulares. De este modo, se dejaba impunes a los legisladores de toda responsabilidad 
civil. Tras el argumento anterior por muchos años se creía que los legisladores se encontraban en la cúspide "de una pirámide jurídica" (Alonso, Leiva, 2011, p.81). Conforme ha pasado el tiempo este concepto ha evolucionado y ha comenzado a desvirtuarse, dando apertura a un sin número de garantías que permiten a quienes en teoría son los más débiles, es decir, los administrados, limitar el poder estatal brindándoles la oportunidad de exigir y hacer responsable al Estado por cada una de sus actuaciones.

En consecuencia de lo anterior, resulta razonable obligar al Estado a resarcir a todos quienes hayan sido víctimas de perjuicios en virtud de su actuar irresponsable, exigiendo una compensación razonada que tiene como hecho generador una ley promulgada de forma inconstitucional, ilegal o sin los procedimientos por norma imperativa exigidos, pues se observaría una injerencia directa de los legisladores.

Por ejemplo, en el ordenamiento jurídico colombiano y español, existe una norma en la cual da lugar a una obligación indemnizatoria por parte del Estado, justamente cuando existe una acción u omisión de las autoridades a causar un daño o perjuicio a los particulares.

En virtud de lo expuesto, se analizará la responsabilidad extracontractual civil por hecho legislativo y los argumentos que dan origen al reconocimiento de dicha responsabilidad. Esto en vista de que actualmente es aceptada por diferentes doctrinarios y jurisprudencia internacional, superando obstáculos que anteriormente impedían accionar en contra del Estado por un "dogma de soberanía”. Esta normativa y jurisprudencia internacional es la que servirá como base para dilucidar nuestros argumentos.

\section{Teorías que asignan responsabilidad al Estado}

Mediante las teorías de Tutela Jurídica, Intervencionismo y Teoría Teológica podremos ejemplificar mejor la responsabilidad estatal. Por su parte, Rousseau da una explicación sobre el Estado y el "pacto social" (Ochoa, 2012, p.3), para que exista una voluntad general de todos. Además, se va designando diferentes funciones, como divi- 
sión de poderes del Estado para que exista un control entre ellos, evitando un despotismo y abuso del poder. Esta división también asegura una vigencia de libertades individuales de las personas, puesto que la vulneración del derecho de un administrado por parte de un poder del Estado debe ser fiscalizado por otro, para determinar el tipo de resarcimiento que merece el administrado.

Para ello también se aplica el concepto del Estado de Derecho, de modo que el administrado sea escuchado en una situación de igualdad ante la ley y que, sin estar en un nivel de inferioridad, pueda exigir la reparación por haber sufrido un perjuicio. Igualmente, el estatus de ciertos derechos garantizados por el Estado es preexistente al mismo, es decir "los derechos se derivan de la dignidad de las personas, pueblos, comunidades y nacionalidades" (CCE, 2019, Sentencia No. 282-13-JP/19, párr. 30), de modo que el Estado no puede desconocerlos según su arbitrio.

Ahora bien, el Estado tiene como fuentes principales de responsabilidad a las teorías de Tutela Jurídica, al Intervencionismo y Teorías Teológicas:

La teoría de la tutela jurídica hace referencia a que el Estado está obligado a responder perjuicios que ocasiona a las personas, mientras estén cumpliendo sus actividades habituales, es por ello, que el Estado puede cometer actos perjudiciales, esto se ve de manera objetiva porque existe una prueba en contrario, pues el Estado se obliga a proteger el patrimonio de las personas (Ochoa, 2012, p.10).

Una sentencia colombiana lo ilustra de mejor manera y dice los siguiente:

Al propio Estado [le] corresponde la salvaguarda de los derechos y libertades de los particulares frente a la actividad de la administración. Así la responsabilidad patrimonial del Estado se presenta como un mecanismo de protección de frente al aumento de la actividad del poder público, el cual puede ocasionar daños que son resultado normal y legítimo de la propia actividad pública, al margen de cualquier conducta culposa o ilícita de las autoridades (CC Col., 1996, Sentencia C333/96, párr.8). 
Sobre la teoría de Intervencionismo, se refiere principios constitucionales que tiene el Estado, ya que, como ente supremo, tiene poderes o facultades exhorbitantes en beneficio de la sociedad. En tal virtud, existe la posibilidad de que cause daño a los habitantes, lo cual generaría la obligación de reparación (Ochoa, 2012, p.11).

Por otro lado, la tendencia teleológica nos indica que el Estado tiene un deber esencial que debe cumplirlo de manera inexorable, y es el de reparar los daños que se produzcan como consecuencia de su actividad. Todo sea por el bienestar colectivo.

Existen otras teorías en las que se le atribuye responsabilidad al Estado como es la Teoría de la representación, esta se basa en culpa in eligiendo o in vigilando, es decir la elección del representante por parte del representado (Ochoa, 2012, p.12). Quienes afirman dicha teoría apoyan al Derecho Civil e indican que es una rama jurídica que se encarga de regular las relaciones que tiene el Estado y los particulares. Así mismo, se encuentra la teoría de la proporcionalidad de las cargas, su razonamiento merece a que los ciudadanos no deben sufrir unos más que otros por las cargas que se imponen en el interés de la sociedad. En tal virtud deben ser indemnizados (Teissier, 1942, p.231).

\section{Conceptos sobre la responsabilidad}

El significado jurídico de la responsabilidad puede obtener diversos conceptos, dependerá de la rama del Derecho que se esté tratando. El Derecho Civil indica quien haya cometido algún acto una omisión y por consiguiente un tercero haya sufrido un daño o detrimento, tiene la obligación de resarcir al individuo que fue afectado y reparar dicho daño mediante una compensación, sea dineraria o no. El daño puede ser personal, patrimonial o moral (Corral, 2003, p.148).

Debemos indicar que una de las finalidades del Derecho Civil es precautelar los bienes protegidos de las personas como el patrimonio, además busca una reparación a una víctima, otorgando tal responsabilidad a quien cometa un acto $\mathrm{u}$ omisión para que responda por el daño o perjuicio frente al sujeto. Para demostrar la presente 
tesis se debe hacer una observación a los elementos que componen a la responsabilidad civil.

La doctrina ha denominado al daño como "el detrimento, perjuicio o menoscabo que se recibe por culpa de otro sea a sus bienes o en cualquiera de sus derechos" (Escriche, 1863, p.192). Cuando nos referimos a daño se puede concluir que es un "fenómeno existencial" (Corral, 2003, p.137) en la vida humana, hechos que se dan por la convivencia entre personas.

Se da una importancia jurídica al daño porque permite que las personas puedan reclamar una indemnización. Por consiguiente, para que exista un resarcimiento, se debe reunir varios requisitos, como la certeza, esto se verifica conforme a hechos ciertos, reales y efectivos (Corral, 2003, p.142). Debe existir una relación directa con el hecho, es muy importante constatar esto para que se pueda exigir una indemnización. Siendo así, se refiere a la relación de causalidad entre el hecho y efecto directo (Alonso, Leiva, 2011, p.81). En cuanto a los daños patrimoniales, se subdividen en daño emergente y lucro cesante. Siendo el daño emergente una perdida actual del patrimonio o como manifiesta la doctrina la discusión real y efectiva del patrimonio de la víctima y el lucro cesante la aspiración del que sufrió el daño a incrementar su patrimonio, producto de su trabajo.

No obstante, el juzgador, haciendo uso de su sana crítica debe analizar de manera fehaciente el lucro cesante porque prácticamente son los daños derivados. El daño no patrimonial no constituye detrimento en el patrimonio de la víctima, allí se encuentra meramente el daño moral, es conceptualizado como "la molestia y el sufrimiento moral o físico que produce un determinado hecho, y este no se aprecie de manera pecuniaria" (Corral, 2003, p.151) de tal forma, la víctima puede exigir una indemnización.

Para efectos del presente trabajo académico, es necesario mencionar la subdivisión entre responsabilidad contractual y extracontractual. En la primera, básicamente se hace referencia a las obligaciones incumplidas de un contrato previo, misma que es un acuerdo pactado con anterioridad por las partes, en caso de que alguna no cumpla 
con lo estipulado en el mismo se dará paso a la responsabilidad. Por otro lado, se encuentra la responsabilidad extracontractual, que se orienta mucho más al Derecho de Daños (Corral, 2003, p.24).

Pues es mucho más amplio porque se debe pagar por las conductas que devienen de la obligación con el deber de no dañar, sin necesidad de tener como fundamento una relación jurídica previa. En los casos de responsabilidad por hecho legislativo, claramente se incurriría en esa segunda categoría: extracontractual, puesto que la obligación de dictaminar leyes nace de la Constitución y no de un contrato directo entre el Legislativo con los ciudadanos.

Ahora bien, se ha realizado un recuento de los conceptos principales sobre el estudio de Derecho de Daños, que se enfoca en las actuaciones cotidianas que generan que de alguna manera la libertad de las personas choque y podría afectar al ejercicio de los derechos de los demás. Existen daños que efectivamente deben ser resarcidos y otros que no, justamente por la relevancia de estos, y tiene mucha injerencia en la economía y en las políticas públicas.

El Derecho de Daños tiene como una de sus funciones principales compensar a quien ha sufrido el daño; se encarga de dejar a la persona en el estado o situación que se encontraba antes de que ocurra el daño. Otra función es la sancionatoria, que busca el resarcimiento a la víctima.

Consideramos un tema sumamente relevante analizar el fenómeno de responsabilidad del Estado causada por hechos del legislador. Pues debemos partir de una regla general de hechos u omisiones por parte de la Administración Pública. Partir también de que el Estado tiene como obligación tutelar los derechos de las personas y de responder frente a la imputación de daños que ocasionen.

Los habitantes de un determinado país, no se encuentran obligados a soportar un detrimento por el hecho de que sea una orden dada por el Estado siempre que esto ocurra. Pues existe una especie de protección a agentes estatales por la soberanía de este. No obstante, se sostiene la tesis de que aquella decisión del Estado se vea como un 
hecho que causó un detrimento a un particular, puede tener caracteres que configuren la antijuridicidad en ese acto, vulnerando así, el deber de tutela de derechos.

\section{Eximentes de responsabilidad}

Dentro de la responsabilidad extracontractual analizada desde la óptica del Derecho Civil, planteando el supuesto hacia ciertas actividades mediante las cuales se pueda inferir la existencia de algún tipo de responsabilidad civil extracontractual por parte del Estado y sus agentes, hay hechos que permiten eximir a dichos órganos administrativos y consigo al propio Estado de ser responsable de los daños causados hacia los particulares en cuanto a la vulneración de derechos tanto individuales como colectivos.

Es por esto que dicha responsabilidad administrativa requiere de un balance y un sistema de contrapesos que permita poner límites a quienes pretenden ejercer dichas acciones en contra de un ente estatal. Esto haciendo referencia a la finalidad única y exclusiva del derecho de daños que extiende su capacidad de resarcimiento a cualquier persona natural o jurídica, y quien haya sufrido un menoscabo tenga la posibilidad de ser resarcido por el responsable del mismo, justificando así un sistema armónico de responsabilidades dejando de lado cualquier interés económico que permita a los individuos generar un enriquecimiento no justificado.

Debido a esto, es necesario la existencia de ciertos eventos o hechos que produzcan una garantía de seguridad jurídica e igualdad de derechos a ambas partes en controversia hechos que a la hora de hablar del demandado le permitan eximirse de la responsabilidad hacia el imputado, de forma que no se encuentre obligado a responder o indemnizar con su propio peculio a la persona víctima del daño alegado.

En consecuencia, de lo mismo, el Estado no podrá ser imputado de ningún tipo de responsabilidad en aquellos hechos donde el nexo causal vínculo del daño que, en efecto, sea producto de su acción administrativa, no sean casualmente directas con el evento dañoso. En 
otras palabras, el Estado y sus órganos administrativos serán eximidos de su responsabilidad al romper debido a un evento en particular su relación directa de causalidad siendo producto de hechos que, a pesar de todas las previsiones, acciones de diligencia y en virtud del estándar de un tercero razonable su resultado dañoso no haya sido posible de resistir, erradicarán en su totalidad dicha responsabilidad.

Considerando que aquellas causas de exoneración son aquellas que impiden de manera clara frenar una imputación evidente hacia el responsable del hecho antijurídico, afectando así la causalidad, desvirtuándola de manera objetiva, en general estos omitirían la posibilidad de ser imputados por acciones dañosas, causas que terminan siendo un mecanismo de protección para el sujeto responsable del daño al atacar uno de los elementos más necesarios será el reclamar la existencia de un daño como la causalidad.

Por su parte, las causales de exoneración en materia de responsabilidad estatal actúan de la misma manera que entre particulares al ser una forma de exencionarse frente a cualquier tipo de abuso del derecho en consideración a una causa imposible de atribuir al no contener un nexo causal evidente, tales hechos permiten esta posibilidad son los siguientes:

\subsection{Fuerza mayor como eximente de responsabilidad extracontractual}

Uno de los supuestos necesarios para considerar una ausencia de responsabilidad es la fuerza mayor, aquella que se puede definir de manera simple pues es la fuerza o acontecimiento cognoscible que actúa sin ningún tipo de previsión, es decir, no deriva de una actividad normal y común. Son hechos externos, de la naturaleza, cuyo efecto por ningún medio y bajo ninguna circunstancia podría preverse, a pesar de cualquier medida de precaución o prevención.

Para configurar el eximente de responsabilidad de fuerza mayor es necesario analizar que el hecho que así se le imputa sea tanto irresistible como imprevisible, que además según la doctrina, el hecho da- 
ñoso resultante de este evento es imposible de atribuir a una persona o en el caso particular al Estado como tal. Por ello según Héctor Patiño define a la fuerza mayor como un evento que de manera sustancial se exterioriza con una fuerza suficiente que resulta imposible de prever o de resistir que originalmente son producto de la naturaleza (Patiño, 2011, p.378).

Cuando aún después de haber tomado todo tipo de precauciones que prepare para un infortunio, el hecho de que los efectos de un evento de fuerza mayor sean inevitables por cualquier persona en la mediana prudencia posible, de forma que al ser un evento ajeno a la voluntad del agente imputado saldría del control del mismo repeler o resistir dicho evento que en su esencia general terminará causando un daño.

Recogiendo el pensamiento de Terregroza Sánchez (2007), define a la fuerza mayor como:

Aquel acto que denota responsabilidad excluyendo del cual con la influencia producida en el caso en particular es un funcionamiento anormal de fuerza que conlleva a situaciones irreversibles e imputables a cualquier servicio que se encuentre sometido a tomar acciones sobre dicho hecho que conduce en causa y efecto a cualquier tipo de resultado dañoso. (p. 203).

Siendo así, es claro que en estos casos donde se haya constituido una evidente fuerza mayor debe tener como requisitos los anteriormente detallados, y añadiendo el considerar que este hecho no depende del obrar del servicio o actividad de la persona imputada sino es un agente externo que se encuentra ínfimamente vinculado con el resultado dañoso aquí alegado por ende el mencionado daño no puede ser imputado ni a quien lo causa ni a quien lo sufre al ser una circunstancia especial reconocida por nuestro ordenamiento jurídico.

\subsection{Hecho de la víctima frente a daños legislativos}

El hecho de la víctima es una de las figuras más controversiales a la hora de considerárselo como eximente de responsabilidad. Este 
actúa como atenuante hacia la responsabilidad que se pretende imputar, pero únicamente de forma parcial (Patiño, 2011, p.391).

Ahora bien, a la hora de comprender esta figura se debe mencionar que aquella refleja que el daño producido, o aquel evento antijurídico que tuvo como causa efecto un daño, fue producido de manera sustancial debido al comportamiento de quien lo sufrió, creado por su acción u omisión a la hora de la producción de dicho daño. Es decir que, en cierta parte, el responsable de lo sucedido es la propia víctima quien debe asumir las consecuencias de su actuar negligente.

Para entenderlo entonces, tenemos que apreciar que este daño tiene como fuente un sujeto quien se expuso de manera deliberada e imprudente hacia aquella actividad que, en el estándar de prueba con un tercero razonable, no toda persona en su mediana condición habría actuado de dicha forma. Visto desde otra óptica, se concluye que este daño se entenderá como un incumplimiento a las normas de cuidado propias de forma que terminaría excluyendo la conducta del imputado al ser la propia víctima quien de manera culposa o dolosa incurrió en dicha actividad dañosa permitiendo así al Estado exonerarse de cualquier tipo de responsabilidad demandada (Corral, 2003, p.204).

El comportamiento de esta víctima rompería el nexo de causalidad entre el hecho antijurídico y el daño al considerarse que el actuar voluntario, consiente y razonable del afectado atento en propia manera hacia sus derechos dejando errada la posibilidad de atribuir dicho evento a la acción o servicio que ofrece el Estado.

Como ejemplo, podría entenderse quienes, durante un operativo policial, intercedan en contra de los agentes del orden y los agredan con la única intención de que el sospechoso a quien se pretendía capturar huya; de modo que tras estos eventos y forcejeos se cause algún tipo de lesión a los manifestantes. Esto desvirtuaría el nexo de causalidad y la conducta realizada por los agentes al obtenerse como acción voluntaria una exposición eminente a ser víctimas de un daño. Se requiere así entonces una co-participación de la víctima desde el punto de vista objetivo en la producción de dicho hecho (Torregroza Sánchez, 2007, p.211). 


\subsection{Hecho de un tercero}

Como parte de las causas de exoneración en cuanto a desvirtuar el contenido de la responsabilidad civil extracontractual, encontramos el hecho de un tercero. Como su propio nombre lo dice, tiene como supuesto de hecho que el causante directo o la persona a quien se le está imputando un daño no es aquella que participo de manera directa ni indirecta en la producción del mismo, esto al ser ajeno a cualquiera de las partes que intervinieron dentro de la producción del mismo en el juicio de responsabilidad. En este sentido, el nexo causal será el requisito indispensable y vinculante para lograr una imputación clara de responsabilidad, quedaría desecho al no encontrarse los sujetos reales siendo a quienes se pretenda exigir la indemnización por los daños tanto causados como sufridos.

Debido a esto es necesario entender que para configurarse dentro de un supuesto de participación de un tercero ajeno a las partes litigantes del daño dentro de un proceso es imperativo que en el mismo se presente este hecho de manera única y exclusiva de tal forma que el hecho de este tercero se torne evidentemente determinante con el daño producido.

Además de ser un hecho que de manera absoluta fue producido por circunstancias nuevamente como es el caso de la fuerza mayor por situaciones imprevisibles e irresistibles para la persona que lo está alegando, de forma que esta termina siendo la única causa determinante del daño donde a forma de ver la participación del imputado este quedaría excluido de cualquier tipo de responsabilidad al ser un agente extraño quien debe ser demandado y exigido de compensar dicho daño.

Es por todos estos argumentos que, mediante un análisis casuístico, el Estado no estaría obligado a responder por ningún tipo de responsabilidad extracontractual si de forma directa no ha sido él quien termine siendo el causante del daño.

De forma que su participación o la de cada uno de los agentes estatales no sean los partícipes de un daño que a manera de verificarse 
los particulares están obligados a reconocer al verdadero artífice del evento antijurídico dejando desvirtuada cualquier alegación existente en contra del Estado en la búsqueda de cualquier tipo de indemnización no podría ser alegada y terminaría estando desecha tanto en vía judicial como en vía administrativa (Enterría, 2005, p.940).

\section{Hecho antijurídico desde la responsabilidad por daño legislativo}

Como parte de un análisis final se considera la responsabilidad estatal frente al daño legislativo, el cual no es más que producto de una actividad que mediante ley ha sido atribuida dentro de uno de los poderes más importantes para el Estado como es el caso del poder legislativo.

Analizando la problemática desde una óptica moralmente objetiva se puede considerar que el Estado en muchos de los casos donde ejerciendo su facultad única y exclusiva de emitir leyes, reglamentos y normas de conducta; así la sociedad logra en el análisis de caso por caso transgredir diversos bienes jurídicos que contemplan en muchos de los casos estas normas vulnerando así desde el plano jurídico los derechos adquiridos por ley, en dicha forma se logra aparejar este tipo de daño con el mal causado por el Estado dentro de la emisión de una norma que producirá efectos contrarios a sus fines constitucionales frente a sus habitantes.

En síntesis, podría existir, pero como Estado y como el máximo órgano encargado de regular las relaciones del bien llamado contrato social, estos hechos vendrían o serían provenientes de hechos no antijurídicos. Es decir que, al analizar el daño generado, en su mayoría de ellos se hablaría de un hecho no ilícito que termina proviniendo de una no solo acción facultada por ley sino comprende además una acción que es parte de las disposiciones legales pertinentes al cuerpo emisor de las mismas (Contreras, 1948, p.94).

Adicionalmente, es difícil comprender que en la mayoría de casos la abstracción es muchas veces indivisible y resulta difícil considerar 
una categorización de perjuicios derivados del actuar sea responsable o no del legislador, de forma que en la teoría general de la responsabilidad extracontractual el Estado sería objeto de cualquier imputación proveniente de su actuar además de ser objeto la víctima de una reparación que se superponga al hecho dañoso, debido a ello es evidente considerar que el estándar general para lograr atribuir al Estado cualquier tipo de responsabilidad debe ir acorde a un análisis de principios rectores en el Derecho Administrativo.

El punto de análisis en considerar cuando el Estado está a través de sus manifestaciones soberanas transgrediendo el principio de igualdad de las cargas públicas, cuando las normas expedidas van en contra de la legítima confianza del pueblo y más aún en contra de la propia Constitución, es decir, violentar de esta manera la confianza legítima trasladada por el pueblo hacia sus representantes así como generar consecuencias irreparables en cuanto a la situación común de los ciudadanos o de cierto segmento de la población.

Es importante mencionar que el Estado en sus facultades debe cumplir con sus responsabilidades legales y primordialmente constitucionales, esto quiere decir, que a pesar de en cierto sentido ser el causante de una infinidad de acontecimientos o hechos dañosos dentro de sus facultades legislativas el límite de su actuar y bajo un régimen de seguridad jurídica debe estar fundando en derecho. Es decir que a la hora de emitir, producir y promulgar una ley esta debe encontrarse sin ningún tipo de anomalía legislativa, donde se promuevan los principios de igualdad, confianza y se pondere de manera específica el bien común o alcance al que se someterá dicha norma, es por esto que dentro de los ordenamientos jurídicos de cada nación hay acciones de contraposición para el control de estas garantías, además de condicionar las actuaciones de los legisladores.

En un segundo plano cualquier Estado y sea cual sea su Constitución política se encuentra eximido de cualquier tipo de responsabilidad siempre que se justifique que las normas promulgadas cumplen con todas las solemnidades de ley, donde se permita comprender que los ciudadanos pertenecientes a dichos Estados se encuentran en la obligatoriedad de renunciar a ciertos derechos en pro 
de un beneficio colectivo, de forma que a la hora de producirse un daño, o de emitirse una norma estos se encuentren sujetos a observar los efectos normativos desde una óptica general dejando de lado su bienestar común por el bienestar de toda la sociedad.

Por otra parte, nos corresponde decir que, dentro de la vigencia efectiva de la norma, el hecho antijurídico se encontraría desvirtuado al contar con reglamentos que permitan su óptima aplicación dando un paso evidente para su entrada en vigor y un tiempo considerable que permita a cada una de las personas prever y prepararse en resistir el daño que dicha norma causará en su vida personal.

El hecho antijurídico entonces no podría ser considerado como un hecho ilícito como tal sino y únicamente en los casos donde el Estado a través de su facultad legislativa por su actuación u omisión configure una desigualdad en las cargas sociales, le otorgue al ciudadano una carga que no se encuentra obligado a resistir.

Es por esto que en cierta medida se hablaría que el hecho antijurídico como tal vendría a ser en los supuestos donde el Estado a través de sus funciones haya emitido normas de carácter inconstitucional o en contra de las disposiciones contenidas en su Carta Política de forma que se encuentren únicamente como responsable al Estado en los casos donde el hecho antijurídico sea de manera exclusiva una carga ilegítima. Donde se encuentre una vulneración de derechos y se omita el conocimiento de los mismos en la norma predecesora es por ello que se considera la antijuridicidad del hecho donde se haya sostenido que en base a cada uno de los supuestos la aplicación de este daño en general producirá una mayor cantidad de beneficios y promulgará al máximo la soberanía y un vivir equitativo entre todos sus participantes.

Debido a esto, la calificación como tal de un hecho jurídicamente ilícito en esta circunstancia quedaría desierta, al encontrarnos en el supuesto donde el acto antijurídico termina siendo como parte de su facultad normativa un hecho acorde a derecho, es decir, que a pesar de la disconformidad que este produzca a la hora de tutelar el cumplimiento a los derechos fundamentales de los particulares. Las 
personas se encuentran obligadas a resistir de mínima forma ciertos daños que sean tradicionalmente provenientes del legislador motivados de manera directa por aumentar y mejorar las condiciones de vida de todos los ciudadanos.

\section{Casos de responsabilidad extracontractual por hecho legislativo}

Una vez que hemos analizado los presupuestos en los que no cabe responsabilidad, procede la revisión de casos en los que se ha declarado al Estado legislador patrimonialmente responsable. Cabe recalcar que este análisis es jurisprudencial y doctrinal con derecho comparado, puesto que en el Ecuador actualmente no se han dado fallos de este tipo. Adicionalmente, el análisis que se propondrá tendrá un carácter mucho más teórico y expositivo que práctico, por lo que no expondrá temas respecto de normas sustantivas ni competencia para proceder a la declaratoria de la responsabilidad estatal.

Desde una perspectiva de derecho comparado, hay múltiples escenarios que nos podrían llevar a la conclusión de esta responsabilidad desde varias perspectivas. Cabe recalcar que hay una distinción doctrinal muy marcada entre la responsabilidad generada por actos $\mathrm{u}$ omisiones de la Administración Pública y la responsabilidad por daños atribuidos a la función legislativa de un Estado.

La principal diferencia es el instrumento público que origina el daño: para la administración es un acto administrativo, para la función legislativa es la ley, en el sentido de la norma escrita, general y permanente producto de las atribuciones constitucionales de dicha función (Enciclopedia Jurídica, Ley, 2020).

\subsection{Responsabilidad por prescripción constitucional o legal}

Volviendo a los escenarios de responsabilidad del Estado legislador, la primera y la más elemental implica el reconocimiento de la misma ley en cuanto a responsabilidad del Estado por su indebida 
aplicación. Cuando la ley prevé que existen casos en los que su aplicación genera un daño susceptible de indemnización, la misma ley delimita los efectos que puede producir y prescribe la antijuridicidad de los efectos que estén por fuera de dicha delimitación.

En el caso de la Constitución Colombiana (Constitución de la República de Colombia 1991), el artículo 90 de la misma prescribe la respuesta patrimonial por daños antijurídicos de la acción u omisión de autoridades, como base constitucional para exigir el resarcimiento de dicho daño.

El artículo 336 de la Constitución colombiana establece de forma directa y unívoca la indemnización a personas que quedan privados del ejercicio de una actividad económica lícita en virtud de una ley que establezca un monopolio, mientras que el artículo 365 en la misma línea prevé indemnización para personas que en virtud de una ley que establezca la reserva estatal de actividades estratégicas o servicios públicos "queden privadas del ejercicio de una actividad lícita" (Constitución de la República de Colombia, 1991, artículo 365).

De forma similar, en España la derogada Ley 30/1992 en su artículo 139 numeral 3 establecía claramente la indemnización en caso de vulneración del principio de igualdad de las cargas públicas (analizado más adelante) en los siguientes términos se contempla que:

Las Administraciones Públicas indemnizarán a los particulares por la aplicación de actos legislativos de naturaleza no expropiatoria de derechos y que éstos no tengan el deber jurídico de soportar, cuando así se establezcan en los propios actos legislativos y en los términos que especifiquen dichos actos (Ley 30, 1992, artículo 139).

\subsection{Responsabilidad por daños originados por una ley inconstitucional}

Un segundo presupuesto igualmente reconocido por más de una legislación y jurisprudencia es el caso de la declaratoria de inconstitucionalidad de una ley. Evidentemente los presupuestos para la 
declaratoria de inconstitucionalidad de una ley rebasan el objeto del presente trabajo, sin embargo, es fundamental señalar los efectos que de ello se procede.

Cuando el Tribunal Constitucional de un Estado declara una norma inconstitucional, dependiendo de la configuración del ordenamiento, su fallo puede tener efectos ex tunc o ex nunc, esto es, no retroactivos o retroactivos (Gozaíni, 2007, p.175).

Cuando el fallo implica un efecto retroactivo, está expresando de forma clara la antijuridicidad de la norma y, por lo mismo, la antijuridicidad de sus efectos. En el caso en que esa norma haya causado un perjuicio a particulares, ese perjuicio es susceptible de ser reparado. Esta es la consecuencia lógica de un acto de la función legislativa que se sale de su competencia constitucional a la cual está sometida. De modo que de toda declaratoria de inconstitucionalidad de una ley es confirmación de que hubo funcionamiento anormal en el ejercicio de la potestad legislativa.

Sin embargo, hay que hacer una distinción clara entre la demanda de indemnización al Estado legislador por el daño producido directamente por la expedición de una norma inconstitucional de la demanda contencioso administrativo en contra de un acto administrativo que tuvo fundamento jurídico en dicha norma. En ambos cabría responsabilidad del Estado, pero la diferencia radica en el modo de presentar la demanda y la autoridad competente para conocerla, y adicional el objeto que se perseguirá en los dos procesos, pues el uno analiza el aspecto constitucional y de posibles vulneraciones de derechos y el otro, que será un proceso judicial ordinario analizará la legalidad de la actuación de un acto específico.

Como un ejemplo entre muchos de este caso, se cita la sentencia del 29 de febrero del año 2000 de la Tercera Sala de lo Contencioso Administrativo del Tribunal Supremo Español (Causa No. 49/1998, 2000). En esta resolución se reconoce los perjuicios causados a determinadas empresas por una ley emitida en 1980 con sentencia de inconstitucionalidad que data de 1996, sentencia que tiene efectos retroactivos de acuerdo con el artículo 40.1 de la Ley Orgánica del 
Tribunal Constitucional español. El perjuicio constituía en una tasa fiscal para un determinado tipo de maquinaria que, al ser declarada inconstitucional la ley, habría sido injustamente desembolsado por los empresarios. A este entender, la Corte establece que:

No puede descartarse que pueda existir responsabilidad, aun tratándose de actos legislativos, cuando la producción del daño revista caracteres lo suficientemente singularizados e imprevisibles como para que pueda considerarse intermediada o relacionada con la actividad de la Administración llamada a aplicar la ley (TCE, Causa No. 49/1998, 2000).

Posteriormente, la Corte descarta la aplicación de la norma que establece responsabilidad para las actuaciones administrativas (en este caso, la Ley de Régimen Jurídico de las Administraciones Públicas) puesto que los hechos se alegan respecto de una ley con declaratoria de inconstitucionalidad:

La ley declarada inconstitucional encierra en sí misma, como consecuencia de la vinculación más fuerte de la Constitución, el mandato de reparar los daños y perjuicios concretos y singulares que su aplicación pueda haber originado, el cual no podía ser establecido «a priori» en su texto (TCE, Causa No. 49/1998, 2000).

De modo que queda claro que el fundamento jurídico de la indemnización no es la obligación de la administración de responder por un daño causado por la ley, sino que la declaratoria de inconstitucionalidad establece la antijuridicidad de dicho daño, y, por lo tanto, la susceptibilidad de que este sea resarcido.

\subsection{Teoría del sacrificio y defraudación de legítimas expectativas}

Se ha analizado casos en los que cierta jurisprudencia y casi la unanimidad de la doctrina reconoce respecto de la responsabilidad del Estado legislador. Sin embargo, existen otras hipótesis, algunas desprendidas de casos concretos como en España y Francia, carácter meramente teórico mediante las que se podría determinar la antijuridicidad del daño causado por una ley sin declaratoria de inconstitucionalidad. 
Una de estas hipótesis, conocida como la teoría del sacrificio, implica el rompimiento por parte de una ley del principio de igualdad de las cargas públicas. Una ley puede implicar una especie de "expropiación" de un derecho patrimonial respecto de un grupo de personas por motivo de interés público. Sin embargo, hay tribunales que han determinado que existen ocasiones en las que no se justifica que por un interés preeminente frente al interés particular se perjudique de manera especial y grave a unos pocos (Alonso \& Leiva, 2011, p.82).

Para ejemplificar esta teoría, presentamos la sentencia icónica del Consejo de Estado Francés del 14 de enero del año 1938 que es conocida como la primera sentencia que establece responsabilidad por el hecho del legislador. En cuanto a los hechos relevantes, la Corte recoge que en 1934 se expidió una ley que prohibía la fabricación y el comercio de crema láctea que se fabricada con otro elemento que no sea leche. Sin embargo, a la fecha la única empresa que operaba de este modo era la Societé des produits laïtiers La Fleurette, siendo esta empresa la única perjudicada por la ley expedida. Citamos parte del contenido de la sentencia recogida para esclarecer las ideas del tribunal:

(...) Considerando que nada, ni en el texto de la ley ni en sus trabajos preparatorios, ni del conjunto de las circunstancias del asunto permiten pensar que el legislador ha querido hacer soportar a la interesada una carga que no le incumbe normalmente; que esta carga, creada por el interés general, debe ser soportada por la colectividad, de lo que se infiere que dicha sociedad La Fleurette tiene fundamentos para demandar que el Estado sea condenado a pagar una indemnización en reparación del perjuicio por ella sufrido. (Instituto Nacional de Administración Pública, 2018)

Tanto esta sentencia como la del 23 de enero de 1963 recogen el precedente de que la vulneración al principio de igualdad de las cargas públicas en una ley constituye un elemento de determinación de responsabilidad estatal, y se fundamenta en la excepcionalidad y gravedad de un perjuicio derivado de esta ley a unos pocos individuos, siendo esta individualidad el criterio de diferenciación del perjuicio de una norma que cause perjuicios a nivel general (Instituto Nacional de Administración Pública, 2018). 
Otra hipótesis implica la vulneración a la seguridad jurídica por defraudación de legítimas expectativas respecto de la gestión del legislador. Esta teoría se denomina vulneración al derecho de confianza legítima (Ruiz, 2001, p.176). Se denomina confianza legítima a las justas expectativas generadas cuando el legislador comienza a expedir normas en función de uno o varios intereses en particular con un perfil lo suficientemente marcado para que los individuos que obedecen a esa ley realicen acciones afirmativas en función de las leyes promulgadas con la confianza de la consecuente actuación de legislador a futuro.

El fundamento doctrinal se asienta en los principios de seguridad jurídica y buena fe. Por supuesto que el legislador, en principio, no tiene obligación alguna de expedir o no una ley, sin embargo, el adoptar cambios normativos que no son razonablemente previsibles en contra de una línea normativa previamente delimitada, genera perjuicios por la adecuación de la conducta económica de los particulares a la situación anterior que consideraban estable. Por consiguiente, el principio de confianza legítima emana del principio de seguridad jurídica del que gozan todos los ciudadanos.

La discusión que cabe respecto de que actuaciones se puede determinar de una violación de dichos principios y si esa ruptura basta proceder a la indemnización de perjuicios. Sobre esta hipótesis, nuevamente recogemos una jurisprudencia de alta relevancia del Tribunal Supremo de España: la sentencia del 5 de marzo de 1993 de la Tercera Sala de lo Contencioso Administrativo (Tribunal Supremo Español Caso No.131/90, 1993).

Los hechos relevantes de dicha sentencia implican una serie de facilidades económicas otorgadas por el Gobierno Español por medio de decretos hacia el sector pesquero. Meses después, se aprueba la Ley de Adhesión a la Comunidad Europea, que implicaba la rebaja de los cupos de pesca de los armadores nacionales. Existe un principio de confianza legítima que los legisladores españoles vulneraron y por ende se le hace acreedores a una responsabilidad patrimonial. 
El caso pesquero, La Unión Europea determinó rebaja de los cupos de pesca, y un sin número de empresas mercantiles invirtieron mucho dinero para la renovación de la flota, el gobierno había dado facilidades para realizar dichas inversiones mediante un real decreto. Posteriormente, la alta instancia jurisdiccional española consideró como daño indemnizable los perjuicios ocasionados mediante el siguiente análisis:

(...) deviene procedente la indemnización cuestionada, habida cuenta, en primer lugar, la existencia de derechos o al menos intereses patrimoniales legítimos, cuyo sacrificio particular se impuso por las determinaciones que hemos relatado, sin que las respectivas sociedades tengan el deber jurídico de soportarlo, y además porque concurren cuantos requisitos exige nuestro ordenamiento para dar lugar a la responsabilidad patrimonial del Estado, esto es daño, no causado por fuerza mayor, efectivo, evaluable económicamente e individualizado, que es consecuencia directa, (nexo causal), de los concretos actos que se aducen y que hemos examinado como determinantes de la lesión patrimonial (...). (Tribunal Supremo Español Caso No.131/90, 1993).

De la argumentación de la Corte se desprende que es el carácter singular de la ley que origina el perjuicio el que genera la obligación de indemnizar, siempre y cuando existe una acción gubernamental positiva previa que estimule la conducta paralizada o una acción estatal que impida una razonable expectativa de la obtención de un beneficio por parte de la víctima, truncado por la acción legislativa.

Tales como incentivos tributarios o facilidades de crédito regulados de forma reiterada por el legislador en función de incentivar cierta conducta económica, de modo que los particulares de forma prudente y razonable se adecúen a la misma. A pesar de que en España existan sentencias en las que la vulneración de este principio también implica la declaratoria de inconstitucionalidad de una norma, no se descarta la indemnización aun a pesar de dicha declaratoria.

Como se ha demostrado, todos los casos en los que se podría determinar la responsabilidad del Estado legislador se busca una manera de probar la antijuridicidad del daño causado por la promulgación de leyes. 


\section{Caso ecuatoriano}

Se ha analizado brevemente las diversas hipótesis en las que correspondería la antijuridicidad del daño cometido por el Estado legislador en jurisprudencia y doctrina europea. Sin embargo, en América Latina son pocos los indicios que tenemos del reconocimiento de esta doctrina.

En cuanto a jurisprudencia regional, en el caso de Colombia y Chile por ejemplo, no hay sentencias que establezcan directamente una responsabilidad por un hecho legislativo fuera de la hipótesis de inconstitucionalidad, si no que las cortes prefieren analizar temas coyunturales que implican por ejemplo la responsabilidad del estado por daños imputables a decretos ejecutivos (Alonso \& Leiva, 2011, p.94) o la antijuridicidad del daño producto de la ruptura del principio de igualdad de las cargas públicas pero sin desprenderlo directamente de un acto del legislador por no ser inconstitucionalidad (Consejo de Estado, Sala Plena de lo Contencioso Administrativo, sentencia del 25 de agosto de 1998, Colombia).

La falta de jurisprudencia presente en el Ecuador sobre este tema no nos disuade a descartar esta posibilidad del todo, puesto que, aunque no hay normas positivas que reconozcan esta responsabilidad, podemos considerar afirmativamente que en el Ecuador existe el suficiente sustento legal para poder establecer la responsabilidad estatal por hecho legislativo.

Comenzando por la Constitución, que en el artículo 233 establece que "no existen servidores públicos exentos de responsabilidad" (CRE, 2008), así como la responsabilidad política de los asambleístas por sus acciones y omisiones, consagrado en el artículo 127 de la misma Carta Magna. Finalmente, la prohibición expresa de la vulneración estatal de derechos en contra de particulares es fundamento suficiente para abrir la posibilidad de este tipo de responsabilidad.

Sin embargo, hay un elemento que es importante considerar en cuanto a la responsabilidad por declaratoria de inconstitucionalidad, que es la posibilidad que ha abierto las puertas a este tipo de responsabilidad. Y es justamente que, en nuestro ordenamiento, las 
sentencias de inconsitucionalidad sólo tienen efecto hacia el futuro, no tienen efecto retroactivo. Según el texto de la Ley Orgánica de Garantías Jurisdiccionales y Control Constitucional:

Las sentencias que se dicten en ejercicio del control abstracto de constitucionalidad surten efectos de cosa juzgada y producen efectos generales hacia el futuro. De manera excepcional se podrán diferir o retrotraer los efectos de las sentencias, cuando sea indispensable para preservar la fuerza normativa y superioridad jerárquica de las normas constitucionales, la plena vigencia de los derechos constitucionales, y cuando no afecte la seguridad jurídica y el interés general (LOGJCC, 2009, art. 95).

De modo que imposibilita replicar el caso colombiano, que implica la responsabilidad estatal por daños producidos por una ley declarada inconstitucional. Esto deja únicamente la posibilidad de que, para buscar hacer responsable al Estado por un hecho legislativo, se intente bajo las teorías doctrinales antes analizadas: la teoría del sacrificio y la de defraudación de legítima confianza, que cabrían considerando nuestro marco legal.

\section{Conclusiones}

Se ha considerado entonces como en ciertos casos, como el Poder Legislativo, servidores públicos gozan de una surte de 'inmunidad' ante los actos realizados como parte de sus funciones, quedando como exentos de responsabilidad. El Estado no puede ser imputado como responsable en aquellos casos en los que o no exista nexo causal o no se compruebe antijuridicidad por su acción legislativa. Entonces, lo que produce es que la sociedad generalmente se vea cohibida de presentar acciones en contra del Legislador y por ende frente a un Estado en ciertos casos abusivo, por justamente tener una contingencia desbalanceada a perder.

En tal virtud se ha plasmado un concepto de respeto hacia el Estado porque sus decisiones son de suma proridad y como regla general es que las normas de carácter general son pensadas y promulgadas para un supuesto beneficio social. 
Agregando a lo anterior podemos concluir que debe crearse una línea jurisprudencial que analice las distintas teorías de responsabilidad sobre aquellos hechos legislativos que resulten ocasionar en cierto modo un daño frente a los particulares, de forma que permita a todos los afectados accionar diversas herramientas que les permitan exigir frente a determinadas decisiones que les generaron un perjuicio, otorgar un resarcimiento que subsane el daño sufrido.

Así mismo, permitir a los particulares exigir frente al Estado la suerte de perjuicios derivados de una responsabilidad extracontractual que tiene su sustento en una disposición pública que aparentemente beneficia a la sociedad pero así mismo puede trasgredir a un principio universal reconocido dentro de nuestro ordenamiento jurídico el cual manifiesta una igualdad dentro de las cargas públicas a soportar por cada individuo y legitimar mediante estas acciones el ejercicio pleno de los derechos fundamentales tutelados por la Constitución y brindar una determinada confianza hacia los órganos jurisdiccionales, además de promover un cambio legislativo que permita de forma expresa aplicar dichas teorías de responsabilidad en la búsqueda de resolver este tipo de controversias.

De igual forma, mediante un análisis de derecho comparado logramos percibir que en diversos ordenamientos jurídicos alrededor del mundo esta idea de responsabilidad extracontractual por daños legislativos no es ajena, por lo cual cada uno de los particulares puedan acceder a diferentes tipos de recursos jurídicos frente a la administración para exigir el respeto hacia cada una de las actividades que desempeñe en libertad de sus derechos.

Y por ende activar todo el aparataje jurisdiccional con el único fin de buscar un balance entre sus intereses afectados con la legalidad de los actos legislativos antítesis de dicha disputa. Pues como lo manifiesta la historia y cómo podemos darnos cuenta según lo analizado anteriormente, esto ha sido un proceso largo y demoroso, es por ello que hemos hecho referencia a países como Francia, España y Colombia, donde se da plena cabida a la figura jurídica que se planea presentar. 
Viendo desde una perspectiva del derecho de daños, se saca a flote la conclusión de que la propuesta del presente trabajo encaja plenamente, pues se analizan conceptos fundamentales, mismos que se lo aterrizan a un caso en concreto, además que mediante este tipo de análisis se observa una actuación sinalagmática entre el Derecho Público y Privado, partiendo de la remoción de legitimidad de todas las actuaciones del poder legislativo, pues justamente es en cuanto a la antijuridicidad de los hechos que hoy no es posible reclamar dicha responsabilidad.

Finalmente, se cree que en Ecuador dicho procedimiento podría ejercitarse por la vía contencioso-administrativa o accionando el caso ante la Corte Constitucional, pues las teorías doctrinarias en las que se fundamentaría una demanda se relacionan específicamente con derechos constitucionales.

Se considera que la temática aquí abordada puede causar una evolución positiva hacia la atribución de responsabilidad estatal y, por lo tanto, un medio más eficaz de control hacia los poderes públicos desde una fiscalización oportuna desempeñada por particulares, dándoles más elementos para contribuir a la formación de una democracia fuerte y participativa, en vistas hacia el futuro.

\section{Referencias Biográficas}

\section{Textos Jurídicos}

Ahumada, M. Á. (2001). Responsabilidad patrimonial del Estado por las leyes incostitucionales o derecho a no ser perjudicado por una ley inconstitucional. Revista Española de Derecho Constitucional, 280-307.

Contreras, G. V. (1948). Derecho Administrativo II Edición. Santiago de Chile: Nacimiento. 
Corral, H. (2003). Lecciones de Responsabilidad Extracontractual. Santiago de Chile: Editorial Jurídica de Chile.

Consuelo Alonso, M., Leiva R. (2011). La responsabilidad del Estado por el hecho del legislador. Revista Estudios Socio-Jurídicos.

Enterría, E. G. (2005). La responsabilidad patrimonial del Estado legislador en el derecho español. Madrid : Aranzandi-Thomson Civitas.

Instituto Nacional de Administración Pública . (2018). Jurisprudencia Administrativa del Consejo de Estado Madrid: Dailoz.

Gozaíni, O. A. (2007). Sobre Sentencias constitucionales y la extensión erga omes. Revista La Ley, 199.

Leiva, I. N. (2010). La Responsabilidad Patrimonial del Estado legislador: Un análisis a propósito de las garantias del contribuyente en el sistema chileno. Revista de Estudios Constitucionales, 171.

Patiño, H. (2011). Las Causas Exonerativas de la Responsabilidad Extracontractual. Revista de Derecho Privado, 367-387.

Santamaría, J. A. (2007). La Teoria de la Responsabilidad del Estado Legislador. Revista de Administración Pública, 60-72.

Teissier, G. (1942). La responsabilité de la puissance publique. Paris: Paul Dupont.

Torregroza Sánchez, J. E. (2007). Responsabilidad extracontractual del Estado por el Hecho del Legislador. Universidad Externado de Colombia.

Valdivia, J. M. (2019). Sobre la Responsabilidad extracontractual de la administracion por daños provocados por sus contrapartes de construccion en el Derecho Chileno. En [H. Alcaraz, A. Vergara] Itinerario latinoamericano del derecho público francés (págs. 539-555). Valencia : Tirant lo Blanch. 


\section{Ensayos Jurídicos}

Ochoa Rodríguez, G. (2012). La responsabilidad extracontractual del Estado por deficiente prestacion de servicios públicos y efectos en nuestra legislacion. Obtenido de Universidad Andina Simón Bolivar https://repositorio.uasb.edu.ec/handle/10644/3019

\section{Revisión de Enciclopedias}

Enciclopedia Jurídica Ley. (27 de 04 de 20020). Enciclopedia Jurídica Ley. Obtenido de Enciclopedia Jurídica Ley: http://www.enciclopedia-juridica. com/d/ley/ley.htm

Escriche, J. (1863). Diccionario Razonado de la Lesgislación y Jurisprudencia, nueva edición anotada . Madrid: Libreria de Rosa y Bouret.

\section{Jurisprudencia Constitucional}

Corte Constitucional del Ecuador, Caso No. 007-15-IN (Corte Constitucional del Ecuador 07 de 06 de 2017).

Corte Constitucional del Ecuador, Sentencia No. 282-13-JP/19 (Corte Constitucional del Ecuador 04 de 09 de 2019).

\section{Jurisprudencia Comparada}

Corte Constitucional Colombiana Sala de lo Contencioso Administrativo, Sentencia C-333/96 (Corte Constitucional Colombiana Sala de lo Contencioso Administrativo 01 de 08 de 1996).

Causa 49/1998 (Tribunal Supremo Español, Sala de lo Contencioso Administrativo 29 de 02 de 2000). 
Tribunal Supremo Español, Sala de lo Contencioso Administrativo, 131/90 (Tribunal Supremo Español, Sala de lo Contencioso Administrativo 05 de 03 de 1993).

\section{Legislación Comparada}

Constitución de la República de Colombia. (04 de 07 de 1991). Colombia.

Congreso de España. Régimen Jurídico de las Administraciones Públicas y del Procedimiento Administrativo Común. [Ley 30/1992)] (26 de noviembre de 1992). 